\title{
An extragonadal germ cell tumor with dermatomyositis: A case report and literature review
}

\author{
YU FUJWARA $^{1}$, NAOKI FUKUDA ${ }^{1}$, AKIHIRO OHMOTO $^{1}$, KENJI NAKANO $^{1}$, MAKIKO ONO $^{1}$, \\ SHINICHIRO TAIRA $^{1}$, JUNICHI TORII ${ }^{2}$, MANABU TAKAMATSU $^{3}$ and SHUNJI TAKAHASHI ${ }^{1}$ \\ Departments of ${ }^{1}$ Medical Oncology; ${ }^{2}$ Head and Neck Oncology and ${ }^{3}$ Pathology, The Cancer \\ Institute Hospital of Japanese Foundation for Cancer Research, Tokyo 1350063, Japan
}

Received April 28, 2020; Accepted July 30, 2020

DOI: $10.3892 / \mathrm{mco} .2020 .2130$

\begin{abstract}
The risk of malignancy in inflammatory myopathy patients is well recognized. However, the incidence of germ cell tumor (GCT) with inflammatory myopathy is low, and most reported cases of GCT also exhibit testicular tumors. Therefore, a case of extragonadal GCT with dermatomyositis (DM) is reported in the current study to better understand this paraneoplastic syndrome. A 53-year-old man presented with bilateral cervical lymph node enlargement. A lymph node biopsy showed embryonal carcinoma, and computed tomography showed multiple lymph node and lung metastases. A period of one month after bleomycin, etoposide and cisplatin (BEP) chemotherapy, this patient developed an ery thematous eruption over the extensor surfaces of bilateral fingers, or Gottron's sign and facial erythema. The patient was diagnosed with DM with a positive anti-TIF- $1 \gamma$-antibody result. High-dose prednisolone was effective, and there has been no evidence of cancer recurrence for over one year. The literature review identified 17 cases of GCT with inflammatory myopathy that have been reported so far, and it was indicated that this is the first case of extragonadal GCT with DM following chemotherapy. This case highlights the importance of monitoring after the completion of cancer treatment, as distinctive dermal and muscular symptoms should cause us to consider the possibility of paraneoplastic inflammatory myopathy.
\end{abstract}

Correspondence to: Dr Naoki Fukuda, Department of Medical Oncology, The Cancer Institute Hospital of Japanese Foundation for Cancer Research, 3-8-31 Ariake, Koto-ku, Tokyo 1350063, Japan

E-mail: naoki.fukuda@jfcr.or.jp

Abbreviations: GCT, germ cell tumor; DM, dermatomyositis, PM, polymyositis

Key words: germ cell tumor, embryonal carcinoma, dermatomyositis, paraneoplastic syndrome

\section{Introduction}

Inflammatory myopathies, i.e., dermatomyositis (DM) and polymyositis (PM), are well recognized in association with malignancies. The first case of malignancy-associated inflammatory myopathy was described in 1916, which occurred with gastric cancer (1). Subsequently, ovarian cancer cases were reported in 1935 (2). Previous studies summarized the type of cancer with inflammatory myopathy. Ovarian, gastrointestinal, and lung cancers and lymphoma are relatively common, but germ cell tumors (GCTs) are rare (3-5). The typical clinical course of paraneoplastic inflammatory myopathy is that dermal and muscular symptoms precede the diagnosis of malignancy. In more than half of cases, the diagnosis of inflammatory myopathy precedes the diagnosis of malignancy $(3,5)$. However, a case of extragonadal GCT with DM that occurred after completing chemotherapy for GCT is presented. On reviewing previous literature describing GCT with inflammatory myopathy, this is the first case of GCT whose primary site was extragonadal and the diagnosis of DM was made after the treatment for cancer. Moreover, its unique clinical course would be useful to inform oncologists that, even after treatment for the cancer itself, dermal and muscular symptoms such as facial erythema can be useful as signs for the diagnosis of paraneoplastic inflammatory myopathy.

\section{Materials and methods}

Information about this case was extracted from the medical records of The Cancer Institute Hospital of the Japanese Foundation for Cancer Research. For the literature review, the search terms to identify previous cases on PubMed were: 'Dermatomyositis, germ cell tumor'; 'dermatomyositis, testicular'; 'polymyositis, germ cell tumor'; and 'polymyositis, testicular'. Articles without abstracts or information about the clinical course were excluded. Articles written in languages other than English were also excluded.

\section{Results}

A 53-year-old man was referred to our hospital with suspected cancer of unknown origin. He complained of cervical lymph node enlargement and underwent contrast computed 
Table I. Initial laboratory data.

A, Complete blood cell

\begin{tabular}{lcc}
\hline Variable & Value & Unit \\
\hline WBC & 5,100 & $/ \mu 1$ \\
Stab+Seg & 54.3 & $\%$ \\
Lymphocyte & 31.2 & $\%$ \\
Monocyte & 11.9 & $\%$ \\
Eosinophil & 1.5 & $\%$ \\
Basophil & 1.1 & \\
RBC & 477 & $10^{4} / \mu 1$ \\
Hgb & 15.9 & $\mathrm{~g} / \mathrm{dl}$ \\
PLT & 217,000 & $/ \mu 1$ \\
\hline
\end{tabular}

\section{B, Biochemistry}

\begin{tabular}{lcc}
\hline TP & 7.7 & $\mathrm{~g} / \mathrm{dl}$ \\
Alb & 4.5 & $\mathrm{~g} / \mathrm{dl}$ \\
LDH & 727 & $\mathrm{IU} / \mathrm{l}$ \\
T-Bil & 0.8 & $\mathrm{mg} / \mathrm{dl}$ \\
AST & 32 & $\mathrm{U} / \mathrm{l}$ \\
ALT & 32 & $\mathrm{U} / 1$ \\
ALP & 294 & $\mathrm{U} / 1$ \\
$\gamma$ GTP & 50 & $\mathrm{U} /$ \\
$\mathrm{CK}$ & 65 & $\mathrm{U} / \mathrm{Ll}$ \\
$\mathrm{BUN}$ & 12.0 & $\mathrm{mg} / \mathrm{dl}$ \\
$\mathrm{Cr}$ & 0.84 & $\mathrm{mg} / \mathrm{dl}$ \\
$\mathrm{eGFR}$ & 75.1 & $\mathrm{ml} / \mathrm{min} / \mathrm{l}$ \\
$\mathrm{Na}$ & 141 & $\mathrm{mEq} / \mathrm{l}$ \\
$\mathrm{K}$ & 4.4 & $\mathrm{mEq} / \mathrm{l}$ \\
$\mathrm{Cl}$ & 105 & $\mathrm{mEq} / \mathrm{l}$ \\
$\mathrm{Ca}$ & 9.1 & $\mathrm{mg} / \mathrm{dl}$ \\
$\mathrm{CRP}$ & 0.06 & $\mathrm{mg} / \mathrm{dl}$ \\
\hline
\end{tabular}

C, Infectious diseases

\begin{tabular}{lcc}
\hline Variable & Value & Unit \\
\hline $\mathrm{HBs} \mathrm{Ag}$ & 0.0 & $\mathrm{IU} / \mathrm{ml}$ \\
$\mathrm{HBs} \mathrm{Ab}$ & 0.45 & $\mathrm{mIU} / \mathrm{ml}$ \\
$\mathrm{HCV} \mathrm{Ab}$ & Negative & \\
$\mathrm{HIV} \mathrm{Ab}$ & Negative & \\
\hline
\end{tabular}

D, Tumor markers

\begin{tabular}{lcc}
\hline Variable & Value & Unit \\
\hline CEA & 1.8 & $\mathrm{ng} / \mathrm{ml}$ \\
SCC & 1.1 & $\mathrm{ng} / \mathrm{ml}$ \\
AFP & 1.1 & $\mathrm{ng} / \mathrm{ml}$ \\
HCG & $<1.0$ & $\mathrm{mIU} / \mathrm{ml}$ \\
$\beta-\mathrm{HCG}$ & $<0.1$ & $\mathrm{ng} / \mathrm{ml}$ \\
\hline
\end{tabular}

\section{E, Coagulation test}

\begin{tabular}{lcc}
\hline Variable & Value & Unit \\
\hline PT & 13.6 & Second
\end{tabular}

Table I. Continued.

\begin{tabular}{lcc} 
E, Coagulation test & & \\
\hline Variable & Value & Unit \\
\hline PT-INR & 0.98 & \\
APTT & 33.2 & Second \\
Fibrinogen & 386 & $\mathrm{mg} / \mathrm{dl}$ \\
D-Dimer & 0.38 & $\mu \mathrm{g} / \mathrm{ml}$
\end{tabular}

WBC, white blood cell; RBC, red blood cell; Hgb, hemoglobin; PLT, platelet; CEA, carcinoembryonic antigen; CA19-9, carbohydrate antigen 19-9; SCC, squamous cell carcinoma; AFP, alpha fetoprotein; HCG, human chorionic gonadotropin; PT, prothrombin time; PT-INR, prothrombin time international normalized ratio; APTT, activated partial thromboplastin time; TP, total protein; Alb, albumin; LDH, lactate dehydrogenase; T-Bil, Total bilirubin; $\gamma \mathrm{GTP}$, gamma glutamyl transpeptidase; CK, creatine kinase; BUN, blood urea nitrogen; $\mathrm{Cr}$, creatinine; eGFR, estimated glomerular filtration rate; CRP, C-reactive protein; HBs Ag, hepatitis B surface antigen; HBs $\mathrm{Ab}$, hepatitis B surface antibody; HCV Ab, hepatitis C antibody; HIV $\mathrm{Ab}$, human immunodeficiency virus antibody.

tomography (CT), positron emission tomography (PET), and diagnostic cytology. Although poorly differentiated cancer was suspected on cytology, the primary site was not detected by imaging modalities. His past medical history included inguinal hernia and appendicitis in childhood, a ureterocele at age 15 years, fracture of the fibula at age 20 years, and ongoing hypertension and hyperuricemia. The patient's medications included amlodipine, valsartan, allopurinol, and diclofenac as needed. His father had prostate cancer at the age of 60 years. He drank alcohol every day, had no smoking history, and had not been exposed to toxins or illegal drugs. He worked as a bank clerk without any contacts with sick people. His vital signs were stable. On physical examination, cervical lymph nodes, $2 \times 2 \mathrm{~cm}$ in size, were palpable bilaterally. Other examinations including chest, abdomen, genitals, extremities, and a neurological examination showed no abnormal findings. Laboratory data showed elevated lactate dehydrogenase $(727 \mathrm{U} / \mathrm{L}$, normal range: 124-222 U/L). The blood cell count was normal, and the chemistry panel showed no other abnormalities. $\alpha$-fetoprotein (AFP) and human chorionic gonadotropin (HCG) were both under the lower limits (Table I). Contrast CT showed enlargement of bilateral cervical lymph nodes (35 mm x $29 \mathrm{~mm}$ ), anterior mediastinal lymph nodes (49 mm x $30 \mathrm{~mm})$, and paraaortic lymph nodes at the L2 vertebral level (25 mm x $18 \mathrm{~mm})$ and multiple lung nodules, but no tumor in the testis (Fig. 1). Gastrointestinal and colorectal endoscopy found no evidence of malignancy. A needle biopsy was performed from a cervical lymph node twice. Histologically, the biopsy specimen showed proliferation of cancer cells forming a sheet-like structure with coagulative necrosis (Fig. 2A). The cancer cells showed enlarged oval nuclei with conspicuous nucleoli and pale cytoplasm (Fig. 2B). The differential diagnoses were squamous cell carcinoma, undifferentiated carcinoma and GCT, and immunohistochemistry showed that the cancer cells were positive for SALL4, OCT4, and CD30 (Fig. 3A-C). AFP, HCG 

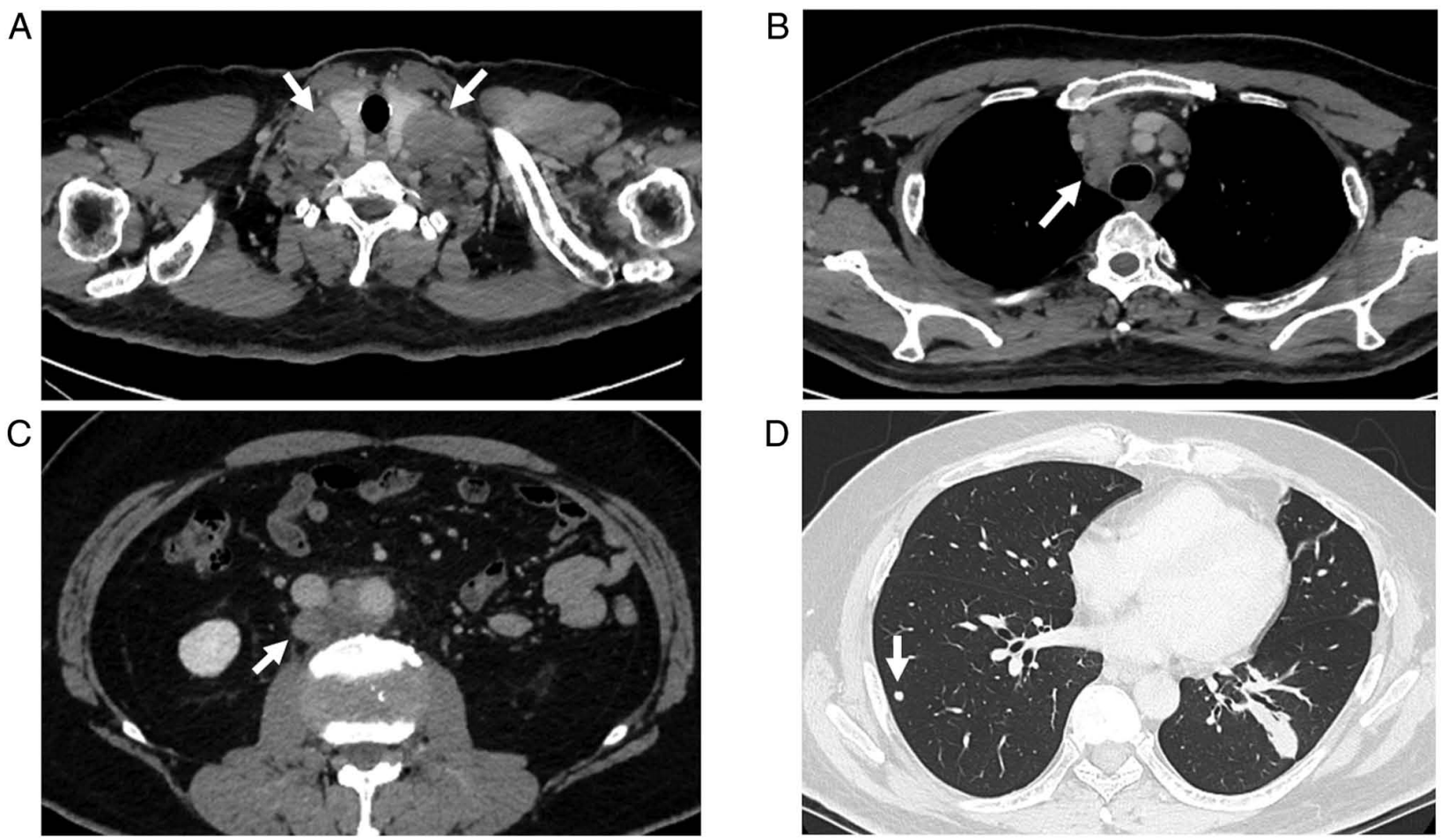

Figure 1. CT images at diagnosis of the germ cell tumor. (A) Enlarged bilateral cervical lymph nodes (arrow). (B) Enlarged bilateral mediastinal lymph nodes (arrow). (C) Enlarged paraaortic lymph nodes (arrow). (D) Lung metastases (arrow).

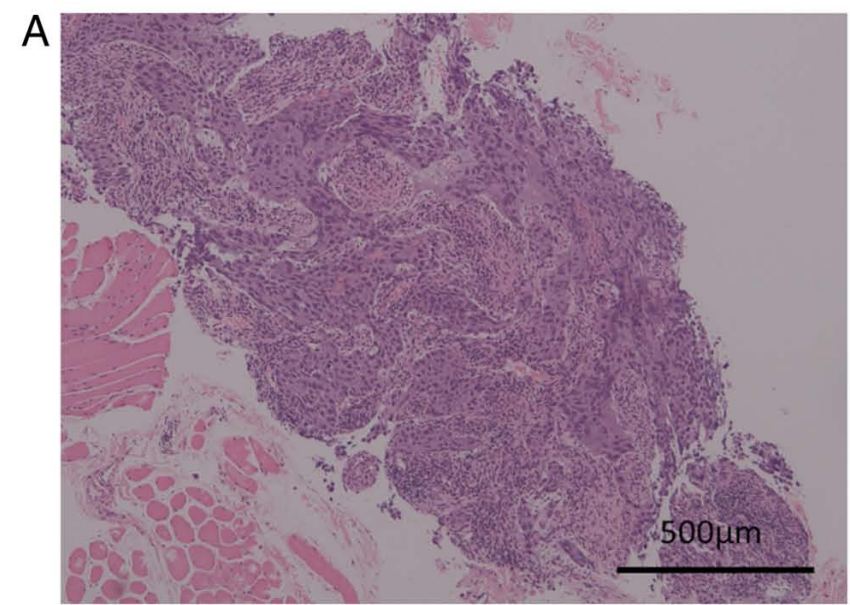

B

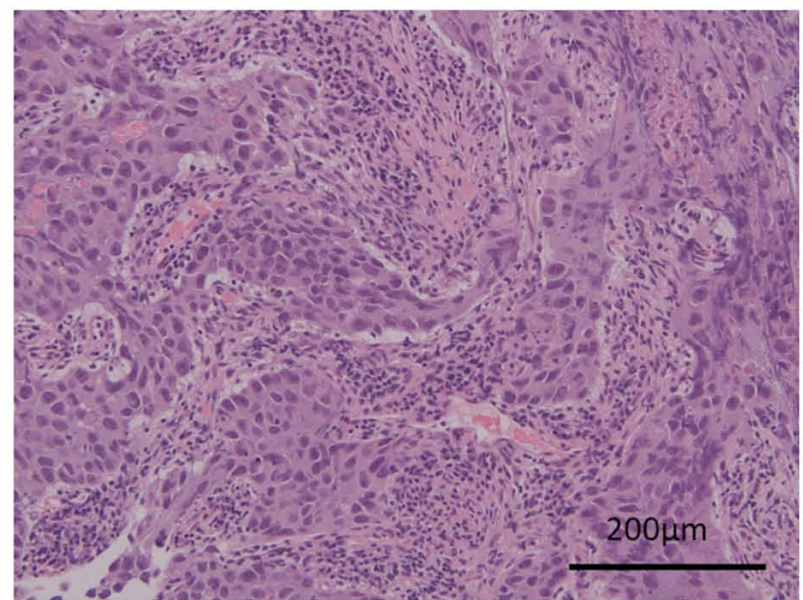

Figure 2. Pathological findings of cervical lymph node biopsy. H\&E staining of cervical lymph node, (A) low-power field and (B) high-power field.

and p63 were totally negative (Fig. 3D-F). Morphologically and immunohistochemically, GCT (embryonal carcinoma) was highly suspected (Figs. 2 and 3). Based on these results, this patient was diagnosed with extragonadal embryonal carcinoma with multiple lymph node and lung metastases. Although isochromosome $12 \mathrm{p}$ was not checked and the primary site could not be confirmed, the primary site was considered to be the mediastinum because the size of the mediastinal lymph node metastases was the largest and cervical lymph node metastases were symmetrical in this patient.

About one month after referral to our hospital, this patient developed bilateral recurrent laryngeal nerve paralyses due to enlarged cervical lymph nodes and was hospitalized. Aspiration pneumonia and respiratory failure occurred.
Thus, a tracheotomy was performed, and respiratory support by continuous positive airway pressure was started. On the following day, chemotherapy (BEP: Bleomycin $30 \mathrm{mg}$ on days 1,8 , and 15 ; etoposide $100 \mathrm{mg} / \mathrm{m}^{2}$ on days $1-5$; and cisplatin $20 \mathrm{mg} / \mathrm{m}^{2}$ on days 1-5) for extragonadal GCT was started. Administration of granulocyte colony-stimulating factor (G-CSF; filgrastim, $75 \mu \mathrm{g} /$ day) was begun on day 6 of the first course of BEP therapy. During this course, the patient's neutrophil count decreased (Grade 4) on day 12, and he developed pneumonia requiring management in the intensive care unit. On the same day, the dose of filgrastim was increased to $150 \mu \mathrm{g} /$ day, and antibiotics including vancomycin and piperacillin/tazobactam were started with mechanical ventilation support. He recovered quickly on day 15 , and the subsequent 
A

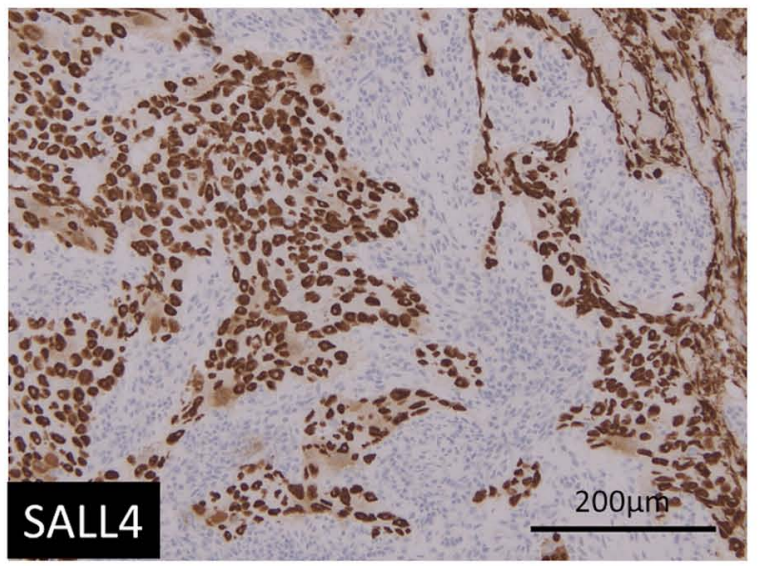

C

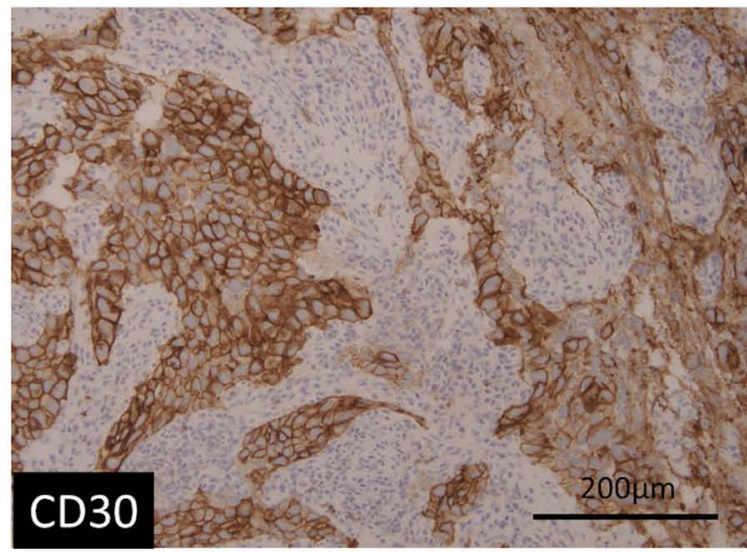

$\mathrm{E}$

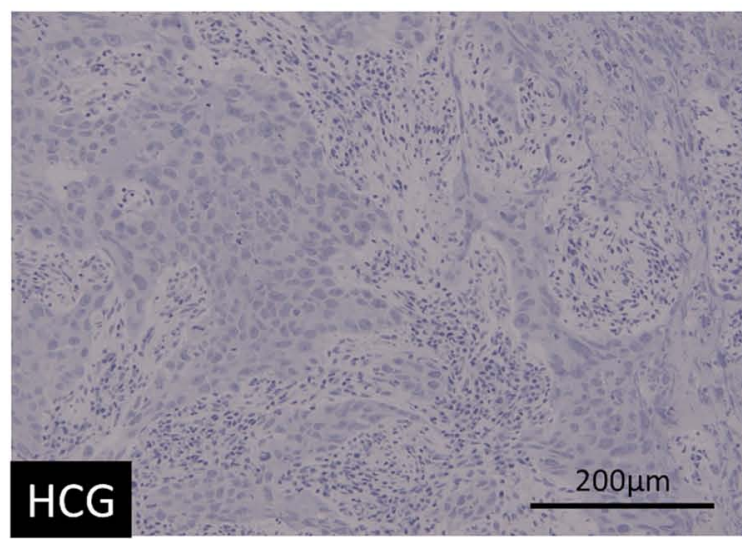

B

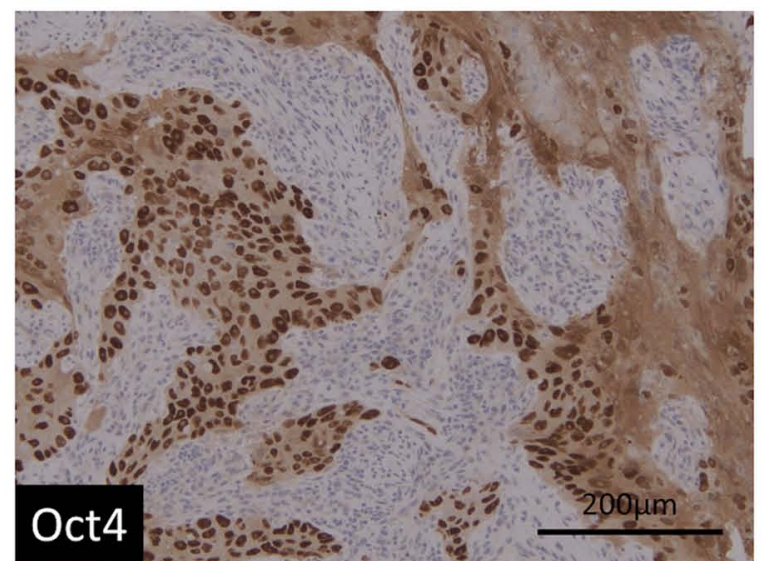

D

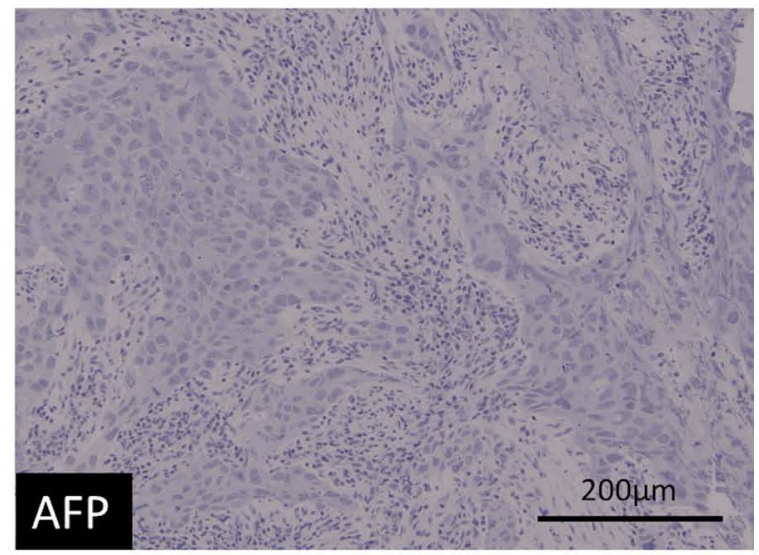

$\mathrm{F}$

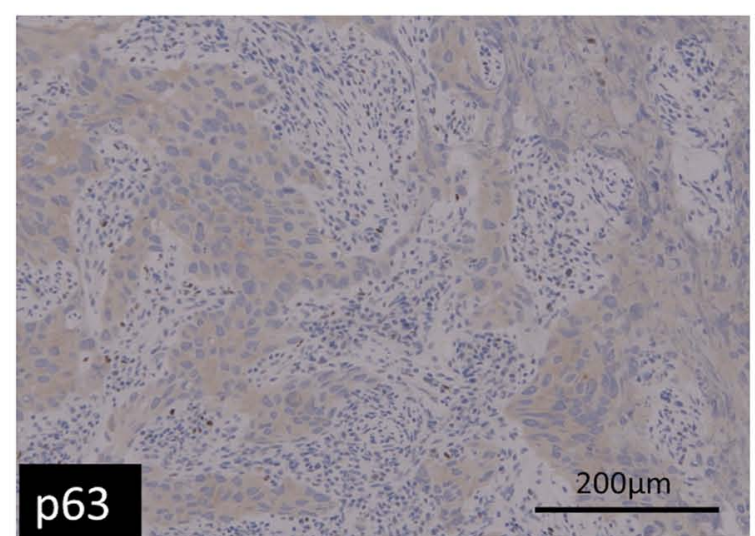

Figure 3. IHC staining results. IHC staining for (A) SALL4, (B) Oct4 and (C) CD30. All are positive. IHC staining for (D) AFP, (E) HCG and (F) p63 are totally negative. IHC, immunohistochemical; CD, cluster of differentiation; SALL4, Sal-like protein 4; Oct4, octamer-binding transcription factor 4.

courses of BEP treatment were continued with prophylactic G-CSF (filgrastim $150 \mu \mathrm{g} /$ day) support. During the first and second courses of BEP treatment, bleomycin administration was skipped on day 15 due to pneumonia and grade 4 neutropenia. However, four courses of the BEP regimen were completed as scheduled two months later. Contrast CT after three weeks of these interventions showed partial response according to the Response Evaluation Criteria in Solid Tumors (RECIST). PET-CT showed no uptake around the tumor lesions, and this patient was followed closely without further treatment. Due to dysphagia caused by bilateral recurrent laryngeal nerve paralyses, percutaneous endoscopic gastrostomy was performed one month after BEP therapy was ended. Swallowing training was started, and the patient was discharged four months after chemotherapy was started.
One month after discharge, this patient developed facial erythema aggravated by sunlight exposure. The use of allopurinol was stopped due to a suspected drug-induced dermatologic adverse event, but the erythema was not improved. Bilateral periorbital edema and an erythematous eruption over the extensor surfaces of bilateral fingers, or Gottron's sign, appeared subsequently with an elevated CK level (562 U/L). Skin biopsy of the facial erythema showed superficial perivascular dermatitis with mucin deposition, consistent with DM. This patient was referred to another hospital for investigation and treatment. Although the embryonal carcinoma maintained partial response at this time, the distinct skin lesions with the results of the biopsy and the positive anti-TIF- $1 \gamma$-antibody result confirmed the diagnosis of DM. Laboratory data at that time are shown in Table II. After starting prednisolone $(1 \mathrm{mg} / \mathrm{kg}=70 \mathrm{mg} /$ body daily $)$, the erythema 
Table II. Laboratory data when dermatomyositis occurred.

\begin{tabular}{lcc}
\hline A, Complete blood cell & & \\
\hline Variable & Value & Unit \\
\hline WBC & 6,100 & $/ \mu 1$ \\
Stab+Seg & 51.6 & $\%$ \\
Lymphocyte & 28.9 & $\%$ \\
Monocyte & 16.9 & $\%$ \\
Eosinophil & 2.1 & $\%$ \\
Basophil & 0.5 & \\
RBC & 373 & $10^{4} / \mu 1$ \\
Hgb & 12.2 & $\mathrm{~g} / \mathrm{dl}$ \\
PLT & 192,000 & $/ \mu 1$ \\
\hline
\end{tabular}

\section{B, Biochemistry}

\begin{tabular}{lcc}
\hline Variable & Value & $\mathrm{Unit}$ \\
\hline $\mathrm{TP}$ & 6.7 & $\mathrm{~g} / \mathrm{dl}$ \\
$\mathrm{Alb}$ & 3.6 & $\mathrm{~g} / \mathrm{dl}$ \\
$\mathrm{LDH}$ & 273 & $\mathrm{IU} / \mathrm{l}$ \\
$\mathrm{T}-\mathrm{Bil}$ & 0.5 & $\mathrm{mg} / \mathrm{dl}$ \\
$\mathrm{AST}$ & 55 & $\mathrm{U} / \mathrm{l}$ \\
$\mathrm{ALT}$ & 27 & $\mathrm{U} / \mathrm{l}$ \\
$\mathrm{ALP}$ & 229 & $\mathrm{U} / 1$ \\
$\gamma \mathrm{GTP}$ & 30 & $\mathrm{U} / 1$ \\
$\mathrm{CK}$ & 562 & $\mathrm{U} / \mathrm{l}$ \\
$\mathrm{BUN}$ & 22.0 & $\mathrm{mg} / \mathrm{dl}$ \\
$\mathrm{Cr}$ & 0.88 & $\mathrm{mg} / \mathrm{dl}$ \\
$\mathrm{eGFR}$ & 71.4 & $\mathrm{ml} / \mathrm{min} / \mathrm{l}$ \\
$\mathrm{Na}$ & 138 & $\mathrm{mEq} / \mathrm{l}$ \\
$\mathrm{K}$ & 4.7 & $\mathrm{mEq} / \mathrm{l}$ \\
$\mathrm{Cl}$ & 102 & $\mathrm{mEq} / \mathrm{l}$ \\
$\mathrm{Ca}$ & 9.7 & $\mathrm{mg} / \mathrm{dl}$ \\
$\mathrm{CRP}$ & 0.88 & $\mathrm{mg} / \mathrm{dl}$ \\
\hline
\end{tabular}

WBC, white blood cell; RBC, red blood cell; Hgb, hemoglobin; PLT, platelet; TP, total protein; Alb, albumin; LDH, lactate dehydrogenase; T-Bil, Total bilirubin; $\gamma \mathrm{GTP}$, gamma glutamyl transpeptidase; CK, creatine kinase; BUN, blood urea nitrogen; $\mathrm{Cr}$, creatinine; eGFR, estimated glomerular filtration rate; CRP, C-reactive protein.

improved, and his prednisolone is being carefully tapered to prevent the recurrence of DM. The post-chemotherapy surgery was omitted because there were multiple lymph node metastases that had been shrinking without uptake on PET-CT. Over the course of the DM, the extragonadal GCT has maintained a partial response. So far, the relapse-free survival and overall survival of this patient after BEP treatment are both sixteen months without recurrence or death.

\section{Discussion}

It is well known that the risk of malignancy in inflammatory myopathy patients is high (6). Although the pathophysiology of malignancy-associated inflammatory myopathy has not yet been determined, many lines of evidence support the relationship of these two different diseases and have shown the incidence, outcome, and prognosis. In inflammatory myopathy, the risk of malignancy differs between DM and PM. The relative ratio of malignancy is approximately 2.4-7.7 times in DM patients and 1.4-2.1 times in PM, respectively. Thus, the relative risk of malignancy is generally higher in DM patients than in PM patients (3-5). The type of malignancy associated with DM and PM is wide-ranging. Ovarian, lung, gastrointestinal, and pancreatic cancers and non-Hodgkin lymphoma are frequently seen in DM patients, and non-Hodgkin lymphoma and lung and bladder cancers are relatively common in PM patients (5). In Japanese patients, gastric, colon, and ovarian cancers are frequently seen in inflammatory myopathy patients (7). However, these population-based studies did not identify GCT patients, and GCT with these myopathies is extremely rare. Only a few cases of GCT including testicular tumors have been reported in association with DM and PM (Table III).

In inflammatory myopathies, several auto-antibodies have been detected. In particular, anti-TIF1 $\gamma$ antibody and anti-NXP2 antibody are known to be associated with malignancy (8). A meta-analysis of six studies involving 312 adult DM patients with malignancy showed that anti-TIF1 $\gamma$ antibody has sensitivity of $78 \%$ and specificity of $89 \%$ for making a diagnosis of cancer-associated DM (9). The positive anti-TIF1 $\gamma$ antibody result in the present case supports the diagnosis of paraneoplastic inflammatory myopathy though the causal relationship cannot be confirmed only through this test (9). There has been only one case of GCT with autoinflammatory myopathy that was anti-TIF1 $\gamma$ antibody-positive, and more cases are needed to discuss the relationship between this antibody and DM in GCT patients (10).

The prognosis of DM and PM with malignancy has been reported to be worse than with typical DM/PM without malignancy (11). However, rather than other solid tumors in the advanced stage, the prognosis of GCT is relatively better. Thus, the prognosis and complications of this patient group should be more precisely determined.

In our review of previous reports, 17 cases mentioning the relationship between GCT and inflammatory myopathy were identified (Table III). The primary site of 15 cases was testis, and that of two cases was extragonadal (retroperitoneum). Pathological results included seminoma, teratoma, intratubular GCT, mixed GCT, and embryonal carcinoma. Only two cases (12\%) had PM, and most cases were associated with DM. As for the timing of onset, five cases (29\%) developed myopathy after treatment for the malignancy. Given these results, the present case appears to be the first case of extragonadal GCT with DM that occurred after treatment for the malignancy. The treatment strategy for paraneoplastic inflammatory myopathy varies from corticosteroid administration to treatment of the malignancy, depending on each case. Although the prognosis of inflammatory myopathy with malignancy is generally poor, cases with GCT seem to have a good prognosis, presumably due to the good prognosis of the GCT itself.

To the best of our knowledge, this is the first case of extragonadal GCT with DM that occurred after chemotherapy was completed and during the period of tumor responsiveness. A delayed diagnosis of DM and PM would decrease the quality of life and negatively affect the survival of a patient. The unique clinical course of the present case reminds us that 


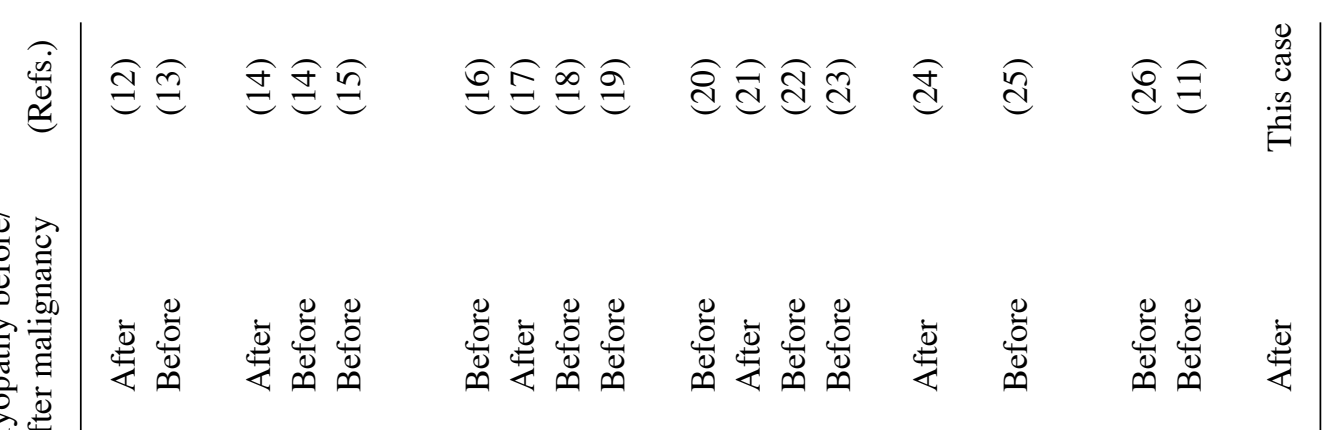

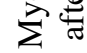

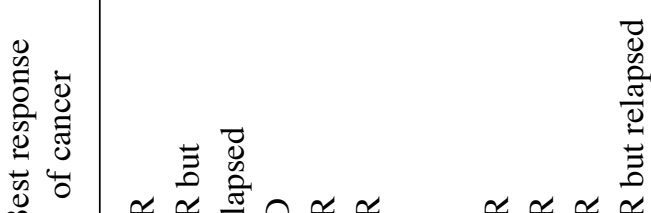

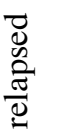

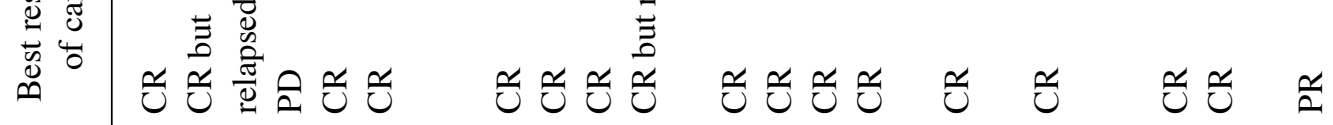

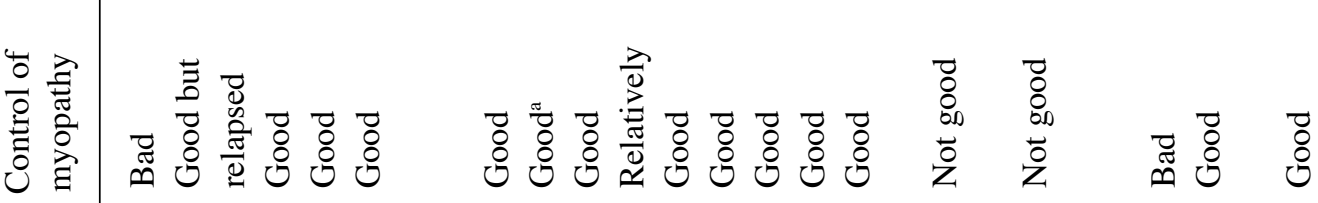

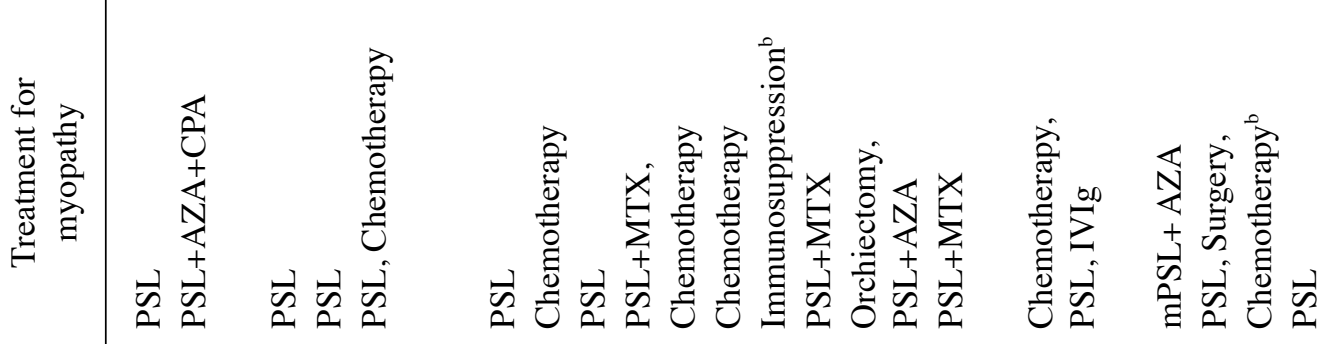

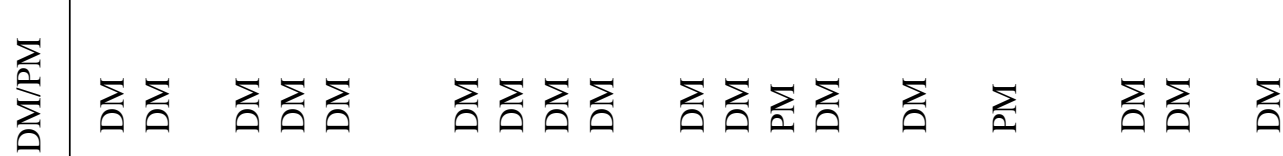

产

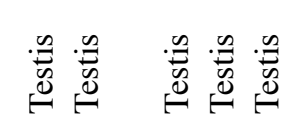

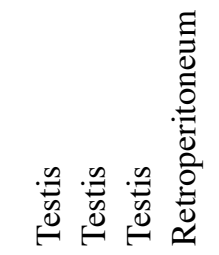

总

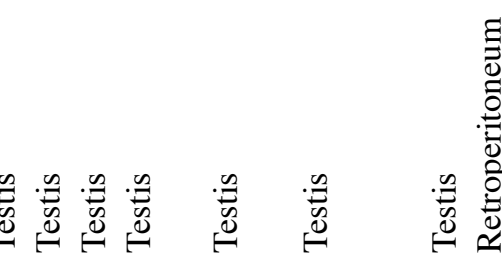

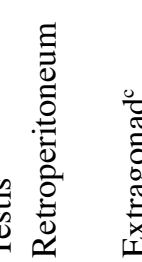

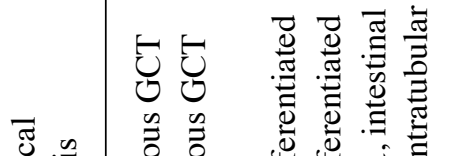

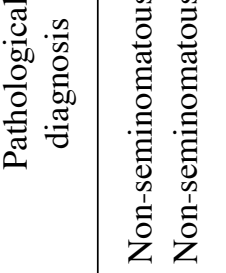

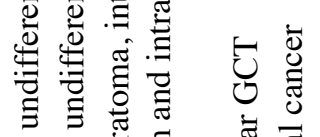

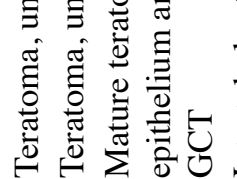

䒕 范

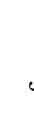


we should consider the possibility of malignancy-associated inflammatory myopathies when we see dermal and muscular symptoms, even after treatment for the malignancy. Because of its rarity and the lack of clarity regarding its pathophysiology, further cases are needed to understand this paraneoplastic syndrome in GCT.

\section{Acknowledgements}

Not applicable.

\section{Funding}

No funding was received.

\section{Availability of data and materials}

The datasets used and/or analyzed during the current study are available from the corresponding author on reasonable request.

\section{Authors' contributions}

YF mainly wrote the manuscript and created the figures and tables; NF cared for the patient, provided professional opinions about writing this report, and revised it; AO, KN, MO, STai and JT cared for the patient and reviewed the manuscript; MT contributed to pathological diagnosis, provided professional opinions about pathological discussion and reviewed the manuscript; STak managed the whole project, and reviewed and revised the manuscript. All authors read and approved the final manuscript.

\section{Ethics approval and consent to participate}

Not applicable.

\section{Patient consent for publication}

Consent for publication was obtained from the patient.

\section{Competing interests}

The authors declare that they have no competing interests.

\section{References}

1. Sterz G: Polymyositis. Berl Klin Wochenschr 53: 489, 1916.

2. Bezecny R: Dermatomyositis. Arch Dermat Syph 171: 242-251, 1935.

3. Buchbinder R, Forbes A, Hall S, Dennett X and Giles G: Incidence of malignant disease in biopsy-proven inflammatory myopathy. A population-based cohort study. Ann Intern Med 134: 1087-1095, 2001

4. Stockton D, Doherty VR and Brewster DH: Risk of cancer in patients with dermatomyositis or polymyositis, and follow-up implications: A Scottish population-based cohort study. Br J Cancer 85: 41-45, 2001.

5. Hill CL, Zhang Y, Sigurgeirsson B, Pukkala E, Mellemkjaer L, Airio A, Evans SR and Felson DT: Frequency of specific cancer types in dermatomyositis and polymyositis: A population-based study. Lancet 357: 96-100, 2001.

6. Qiang JK, Kim WB, Baibergenova A and Alhusayen R: Risk of malignancy in dermatomyositis and polymyositis. J Cutan Med Surg 21: 131-136, 2017.
7. Azuma K, Yamada H, Ohkubo M, Yamasaki Y, Yamasaki M, Mizushima M and Ozaki S: Incidence and predictive factors for malignancies in 136 Japanese patients with dermatomyositis, polymyositis and clinically amyopathic dermatomyositis. Mod Rheumatol 21: 178-183, 2011.

8. Fiorentino DF, Chung LS, Christopher-Stine L, Zaba L, Li S, Mammen AL, Rosen A and Casciola-Rosen L: Most patients with cancer-associated dermatomyositis have antibodies to nuclear matrix protein NXP-2 or transcription intermediary factor $1 \gamma$. Arthritis Rheum 65: 2954-2962, 2013.

9. Trallero-Araguás E, Rodrigo-Pendás JÁ, Selva-O'Callaghan A, Martínez-Gómez X, Bosch X, Labrador-Horrillo M, Grau-Junyent JM and Vilardell-Tarrés M: Usefulness of anti-p155 autoantibody for diagnosing cancer-associated dermatomyositis: A systematic review and meta-analysis. Arthritis Rheum 64: 523-532, 2012.

10. Taki E, Shimizu M, Soeda Y, Shirai M and Muro Y: Anti-TIF1- $\gamma$-positive young adult dermatomyositis with germ cell tumour. Eur J Dermatol 26: 623-624, 2016.

11. Airio A, Kautiainen $\mathrm{H}$ and Hakala M: Prognosis and mortality of polymyositis and dermatomyositis patients. Clin Rheumatol 25: 234-239, 2006.

12. Fife RS, Williams S and Eyanson S: Dermatomyositis associated with treated testicular carcinoma. J Rheumatol 11: 397-398, 1984.

13. Barker RA, Currie DC, Horwich A and Spiro SG: Metastatic non-seminomatous germ cell tumour and dermatomyositis. Postgrad Med J 66: 59-60, 1990.

14. Clayton AJ and Mead GM: Germ cell cancer and dermatomyositis. Clin Oncol (R Coll Radiol) 10: 56-58, 1998.

15. Hayami S, Kubota Y, Sasagawa I, Suzuki H, Nakada T and Motoyama T: Dermatomyositis associated with intratubular germ cell tumor and metastatic germ cell cancer. J Urol 159: 2096-2097, 1998.

16. Ishizawa T, Mitsuhashi Y and Kondo S: Dermatomyositis associated with testicular tumour with elevation of serum lactate dehydrogenase (LDH) isoenzyme-1. Acta Derm Venereol 79: $167,1999$.

17. Di Stasi SM, Poggi A, Giannantoni A and Zampa G: Dermatomyositis associated with testicular germ cell cancer. J Urol 163: 240, 2000

18. von Heyden B, Kliesch S and Nashan D: Re: Dermatomyositis associated with testicular germ cell cancer. J Urol 164: 2030, 2000.

19. Vattemi G, Tonin P, Martignoni G, Filosto M, Marchioretto F, Rizzuto $\mathrm{N}$ and Tomelleri G: Dermatomyositis and retroperitoneal germ cell cancer. Eur Neurol 45: 52-53, 2001.

20. Yoshinaga A, Hayashi T, Ishii N, Ohno R, Watanabe $\mathrm{T}$ and Yamada T: Successful cure of dermatomyositis after treatment of nonseminomatous testicular cancer. Int J Urol 12: 593-595, 2005.

21. Curiel RV, Brindle KA, Kressel BR and Katz JD: Dysphagia after testicular cancer. Arthritis Rheum 52: 3712, 2005.

22. Singhal N, Hissaria P, Joshi R and Nayagam S: Inflammatory myopathy and cancer: Rare association of seminoma testes and polymyositis. Intern Med J 38: 295-297, 2008.

23. Dourmishev LA, Popov JM and Rusinova D: Paraneoplastic dermatomyositis associated with testicular cancer: A case report and literature review. Acta Dermatovenerol Alp Pannonica Adriat 19: 39-43, 2010.

24. Tan E, Young D, McLaren B and Wright A: Early-stage testicular cancer: A rare association with dermatomyositis. Australas J Dermatol 51: 139-141, 2010.

25. Kamei J, Kyono Y, Yamada Y, Shinohara M and Homma Y: Life-threatening polymyositis associated with non-seminomatous testicular cancer: A case report. Hinyokika Kiyo 58: 361-364, 2012 (In Japanese).

26. Norrenberg S, Gangji V, Del Marmol V and Soyfoo MS: Diffuse muscular pain, skin tightening, and nodular regenerative hyperplasia revealing paraneoplastic amyopathic dermatomyositis due to testicular cancer. Case Rep Rheumatol 2012: 534236, 2012.

This work is licensed under a Creative Commons Attribution-NonCommercial-NoDerivatives 4.0 International (CC BY-NC-ND 4.0) License. 